Editorial

\title{
The efficacy of intravitreal dexamethasone implants for non infectious posterior segment uveitis: increasing the uveitis armamentarium
}

\author{
Dai Ni Ong FRANZCO${ }^{1}$ and Lyndell L Lim DMedSci FRANZCO ${ }^{1,2,3}$
}

1. Department of Ophthalmology, Royal Victorian Eye and Ear Hospital, Melbourne, Victoria, Australia

2. Centre for Eye Research Australia, Melbourne, Victoria, Australia

3. Department of Surgery, University of Melbourne, Melbourne, Victoria, Australia

Correspondence: Lyndell Lim, Department of Ophthalmology, Royal Victorian Eye and Ear Hospital, Melbourne, Victoria, Australia

Funding sources / Financial disclosure: None Conflict of interest: None

This is the author manuscript accepted for publication and has undergone full peer review but has not been through the copyediting, typesetting, pagination and proofreading process, which may lead to differences between this version and the Version of Record. Please cite this article as doi: 10.1111/ceo.13694

This article is protected by copyright. All rights reserved. 
Uveitic macular oedema (UME) is a common complication affecting many types of uveitis. It is the most common cause of moderate visual loss (with visual acuities ranging from 6/12-6/60) in patients with uveitis. ${ }^{1}$ It is often recurrent and does not self-resolve. Chronic CME leads to retinal structure damage and irreversible vision loss. In this editorial, we will discuss a practical treatment algorithm for UME.

Prior to treatment, infectious and masquerade causes of a patient's uveitis must be excluded with a thorough history, dilated fundus examination and targeted serological and imaging investigations. Strong caution is warranted with the used of injectable steroids when there is any possibility of an infection. There are case reports of uncontrollable spread of retinitis in the setting of inadvertent use of depot corticosteroid injections in unrecognised toxoplasmosis or viral retinitis, with disastrous visual outcomes. ${ }^{2}$ With the current rise in syphilis which has now reached epidemic proportions in key population, ${ }^{3}$ syphilis serology should be included as a screening test for all cases of uveitis.

With the exception of UME secondary to acute anterior uveitis, topical steroid drops are not adequate as monotherapy. High doses of oral corticosteroids (average dose between $40-60 \mathrm{mg}$ ) with rapid taper is the usual treatment of choice when UME is bilateral, due to its rapid onset of action. However, the systemic side effects of oral corticosteroids limit their long term use, with the acceptable "safe" dose currently being set at $<=7.5 \mathrm{mg} /$ day. $^{4}$

Injectable depot corticosteroids are the treatment of choice when UME is unilateral. The caveat is that there are limitations to their repeated use as mono therapy for persistent intermediate, posterior and panuveitis, as demonstrated by the MUST 7year study results. This randomised prospective clinical trial showed that the group treated with regional corticosteroid alone (Retisert ${ }^{\circledR}$, Bausch + Lomb, Rochester, NY, 
USA) had worse visual outcomes in the long term than systemic immunosuppression. This was postulated to be due to permanent structural sequelae from severe relapses in uveitis activity that occurs when the steroid implants are suddenly depleted, in comparison to the more gradual and controlled step wise reduction in treatment that is possible with reducing systemic treatment. ${ }^{4}$ Thus, in persistent non infectious intermediate, posterior or panuveitis, injectable depot steroid corticosteroids are best used as rescue therapy or adjunctive treatment with systemic immunosuppression, where it is used to treat persisting UME after the associated inflammation has been largely controlled with systemic steroid sparing agents.

Once the clinical decision is made to use an injectable steroid, our options are either periocular steroid injection or intravitreal therapy where preparations include triamcinolone or Ozudex ${ }^{\circledR}$ ( Allergan plc, Dublin, Ireland). Ozurdex is a dexamethasone implant containing 700ug of preserverative-free dexamethasone. TGA-approved for non-infectious posterior uveitis. Its use is funded by Medicare and accessible in Australia through the PBS for the indication of non-infectious posterior uveitis, as well as diabetic macular oedema and branch retinal vein occlusion. It uses a 23 gauge injector, with a shelved approach used to enter the sclera.

So which is the best option for the local treatment of UME? This was recently addressed by the POINT trial, ${ }^{5}$ a prospective randomised clinical trial with 3 arms: periocular triamcinolone acetonide (Kenalog, Bristol-Myers Squibb Company, Princeton, $\mathrm{NJ})$, intravitreal triamicinolone $\left(4 \mathrm{mg} / 0.1 \mathrm{ml}\right.$ triamcinolone - Triesence ${ }^{\mathrm{TM}}$, Alcon Pharmaceuticals, Fort Worth, TX) and Ozudex ${ }^{\circledR}$. This study showed that either of the intravitreal steroids were more effective than periocular steroids in reducing macular thickness: $39 \%$ in the intravitreal triamicinolone group, $46 \%$ in the 
implant group versus $23 \%$ in the periocular group. Visual acuity gains were also better in the intravitreal groups, where the difference was not regained by the periocular group after they were switched to intravitreal therapy.

The risk of IOP rise in injectable steroid is well known. Firstly, risk profiling of our patients into groups of pre-existing glaucoma, known steroid responders and no history of glaucoma is helpful. Secondly, local steroid injections are generally associated with moderate IOP increase of $24-29 \mathrm{mmHg} .{ }^{5}$ The risk of IOP $>30 \mathrm{mmHg}$ was infrequent. This was demonstrated in the POINT trial: among the 185 eyes which received injections and repeated injections, only 4 in the periocular group, 5 in the triamcinolone group and 3 in the Ozurdex had severe IOP $>30 \mathrm{mmHg}$. All were controlled medically with no eyes requiring glaucoma surgery. Compared to periocular injections, the intravitreal injections were on average 2 times more likely to cause moderate IOP increases between $24 \mathrm{mmHg}$ and $30 \mathrm{mmHg}$. There was no significant difference in this risk between the intravitreal triamcinolone and implant groups. $^{5}$

Cataract is another known adverse effect of regional steroid, with a reported incidence of $20-30 \%$, with little difference between periocular ${ }^{6}$, intravitreal triamcinolone ${ }^{7}$ or Ozudex studies. ${ }^{8}$ Onset is usually 12 months after the injection, with an increased rate with repeated injections. ${ }^{8}$

McCartney's and colleagues paper, published in this issue of CEO provides us with a valuable insight into the "real world" use of Ozurdex in 20 eyes with UME from noninfectious uveitis. ${ }^{9}$ The vast majority (95\%) of eyes achieved significant central retinal thickness reduction, with $61 \%$ of the eyes having had an improvement of best corrected visual acuity. Significantly, $90 \%$ of the patient group were able to reduce their oral steroid dose to $<7.5 \mathrm{mg} /$ day. 
The key strength of this paper is that the patient sample reflects the population of patients that we see in our practices. It includes those with refractory disease and eyes with pre-existing structure damage. The follow up of the study is also longer than most, with a mean follow up of 14 months and is thus able to provide valued information regarding the delayed side effects of intravitreal steroid, such as development of cataracts.

Consistent with the POINT trial, McCartney et al showed the duration of the action of the implant was about 3-4 months. Even though the paper did not have any vitrectomised eyes, there is evidence that Ozudex would have similar efficacy and duration of action in vitrectomized as nonvitrectomized eyes, ${ }^{10}$ unlike intravitreal triamcinolone.

In conclusion, untreated UME will lead to visual loss. The key to treating UME is to first control the associated inflammation, and in persisting forms of non infectious uveitis, maintain control of the inflammation using systemic immunosuppression or steroid sparing agents where required. As demonstrated by Maccartney and colleagues, once the inflammation has been controlled, if UME persists, then regional corticosteroid should be used as "top up" treatment, or for the treatment of cases of unilateral acute relapses of uveitis activity. Although these treatments are associated with raised intraocular pressure, this occurs in the minority and the degree of the rise is moderate and can be medically controlled. Thus, Ozurdex, which is now available in Australia for the treatment of UME, is a useful addition to our armamentarium to treat non infections uveitis and UME. 


\section{REFERENCES}

1. Tomkins-Netzer O, Lightman S, Drye L, Kempen J, et al. Multicenter Uveitis Steroid Treatment Trial Research G. Outcome of Treatment of Uveitic Macular Edema: The Multicenter Uveitis Steroid Treatment Trial 2-Year Results. Ophthalmology 2015; 122: 2351-9.

2. Yamamoto $\mathrm{Y}$, Kato $\mathrm{Y}$, Tabuchi $\mathrm{H}$ et al. Case of cytomegalovirus retinitis aggravated by sub-Tenon injection of triamcinolone acetonide with subsequent metastatic liver cancer. Clin Ophthalmo/ 2013; 7: 411-5.

3. Ong D, Bhardwaj G, Ong J et al. Keeping an eye on syphilis. Aust Fam Physician 2017; 46: 401-4.

4. Writing Committee for the Multicenter Uveitis Steroid Treatment T, Follow-up Study Research G, Kempen J H et al. Association Between Long-Lasting Intravitreous Fluocinolone Acetonide I mplant vs Systemic Anti-inflammatory Therapy and Visual Acuity at 7 Years Among Patients With Intermediate, Posterior, or Panuveitis. JAMA 2017; 317: 1993-2005.

5. Thorne JE, Sugar EA, Holbrook JT et al. Multicenter Uveitis Steroid Treatment Trial Research G. Periocular Triamcinolone vs. Intravitreal Triamcinolone vs. Intravitreal Dexamethasone Implant for the Treatment of Uveitic Macular Edema: The PeriOcular vs. INTravitreal corticosteroids for uveitic macular edema (POINT) Trial. Ophthalmology 2019; 126: 283-95.

6. Sen HN, Vitale S, Gangaputra SS et al. Periocular corticosteroid injections in uveitis: effects and complications. Ophthalmology 2014; 121: 2275-86.

7. Gillies MC, Simpson JM, Billson FA et al. Safety of an intravitreal injection of triamcinolone: results from a randomized clinical trial. Arch Ophthalmo/ 2004; 122: $336-40$.

8. Tufail A, Lightman S, Kamal A et al. Post-marketing surveillance study of the safety of dexamethasone intravitreal implant in patients with retinal vein 
occlusion or noninfectious posterior segment uveitis. Clin Ophthalmo/ 2018; 12: 2519-34.

9. McCartney M, McCluskey P, Zagora S. Intravitreal dexamethasone implants for non-infectious uveitis. Clin Experiment Ophthalmol 2019; 47: pp-pp.

10. Cevik SG, Yilmaz S, Cevik MT et al. Comparison of the Effect of Intravitreal Dexamethasone Implant in Vitrectomized and Nonvitrectomized Eyes for the Treatment of Diabetic Macular Edema. J Ophthalmo/2018; 2018: 1757494. 


\section{University Library}

\section{- M M N E R VA A gateway to Melbourne's research publications}

Minerva Access is the Institutional Repository of The University of Melbourne

Author/s:

Ong, DN;Lim, LL

Title:

The efficacy of intravitreal dexamethasone implants for non-infectious posterior segment uveitis: Increasing the uveitis armamentarium

Date:

2019-12-01

Citation:

Ong, D. N. \& Lim, L. L. (2019). The efficacy of intravitreal dexamethasone implants for non-infectious posterior segment uveitis: Increasing the uveitis armamentarium. CLINICAL AND EXPERIMENTAL OPHTHALMOLOGY, 47 (9), pp.1119-1121. https://doi.org/10.1111/ ceo.13694.

Persistent Link:

http://hdl.handle.net/11343/286686 